\title{
State Anarchy and Collective Decisions: Some Applications of Game Theory to Political Economy
}

Alex Talbot Corum

Palgrave, Basingstoke, 2001, 176pp.

ISBN: 0333779320.

Contemporary Political Theory (2003) 2, 135-136. doi:10.1057/palgrave.cpt.9300061

The aim of this book is to introduce the reader to the application of game theory to foundational questions in political economy concerning whether a state is needed to provide security of person and property, and orderly processes of collective decision making. Following the contractarian tradition going back at least as far as Hobbes and Locke, these questions are posed in terms of whether rational individuals in an essentially institution-free state of nature could overcome collective action failures, achieving Pareto-efficient equilibrium. Most of the models covered suggest that this will not necessarily be the case.

This approach has been used by a number of authors in recent years, and the terrain will be familiar to many political theorists. Where this book scores is, first, in bringing together a wide range of relevant recent work as well as covering issues like repeated games and evolutionary games familiar from the work of Michael Taylor, Robert Axelrod and Robert Sugden, among others. For instance, Chapter 4 covers games that model struggles over property, where there is a trade-off for the individuals between producing, stealing, and guarding. Second, the last three chapters cover the question of whether satisfactory, democratic ways of agreeing on a division of the joint gains from moving to the Pareto-frontier can be found, supposing that some way of overcoming collective action failure exists and that joint decisions can be made binding. While these questions are familiar ones in social choice theory, they are seldom brought together with the foundational issues dealt with in earlier chapters.

Corum's main emphasis is on exposition of the models. Although he aims to introduce readers to the relevant literature, those unfamiliar with game theory will not find the details of the modelling particularly easy to follow, although the technical conclusions are clearly stated. It is unfortunate that the more mathematical parts of the text contain numerous typographic errors and discrepancies in notation. It is not always obvious that steps in the technical argument are correct.

Corum deliberately leaves it largely up to the reader to draw inferences from the models covered about such large questions as the necessity of the state, 
whether the state could be a minimal one merely protecting a person or whether, in addition, it would need to define property rights, and whether the failures of democratic social choice processes are as significant as authors like Riker have suggested. While there are certainly different 'readings' of the technical results he covers, which might justify leaving it to the intelligent reader, many political theorists would probably prefer to see a more substantial exposition of what these readings might be.

How useful a conceptual move is it to start lines of normative argumentation from the sort of institution- and norm-free premises that Corum uses? If the historical origins of the state are as a protection racket creaming off surplus from settled agricultural production, it might be more relevant to ask under what conditions will the state find it rational to grant efficient property rights, as authors like Douglas North and Itai Sened have, rather than implicitly justifying the state in terms of the functional need for such rights. In a normative argument, it should be the case that 'ought implies can'; and questions about what the state can do are impossible to answer in the historical abstract. Whereas authors like Michael Taylor and Elinor Ostrom start from the historically grounded reality of communities to show how they provide possibilities for cooperation, the models that Corum discusses load the normative dice in favour of the need for centralized authority by ignoring communal institutions and the social capital they embody. The problems social choice theory identifies as endemic to democracy are actually far less concerning to the extent to which there is a consensus on the social good and a tendency to balance self interest and social interest in voting. How much actually flows from models that ignore the way that democracies can sometimes promote consensus and citizenship?

In summary, those looking for a way into up-to-date themes in the technical literature, surrounding foundational questions in political economy, will benefit from reading Corum's book. It will work best for them if they take the time to sort out in their own minds the conceptual issues around this sort of approach to political economy and what does and does not flow from the models.

Hugh Ward University of Essex. 